\title{
LÓGICAS DO IMAGINÁRIO PÓS-HUMANO E A PRODUÇÃO CULTURAL DE RECEPÇÃO JUVENIL
}

\author{
LOGICS OF THE POSTHUMAN IMAGINARY AND THE \\ CULTURAL PRODUCTION OF YOUTH RECEPTION
}

MARIA ZILDA DA CUNHA*
mariazildacunha@hotmail.com

MARIA AUXILIADORA FONTANA BASEIO**

mbaseio@uol.com.br

É fato que a revolução tecnológica dos últimos tempos tem potencialmente provocado mutações inauditas nos mais diversos domínios da vida humana. As transformações operadas afetam profundamente as condições sociais, culturais e antropológicas; novas subjetividades são geradas e as tecnologias da inteligência tornam-se cada vez mais aptas a abrigá-las, no contexto de comunidades adaptativas. São desafios que vêm motivando a busca de caminhos para compreensão das complexidades que esse novo contexto evoca. No estreito diálogo com essa realidade, projetam-se representações, sobretudo nas artes. As produções culturais voltadas à recepção juvenil mostram-se como território privilegiado para manifestações de um imaginário que se alia a representações de um estágio que está sendo denominado de pós-humano. Em narrativas que abrigam esse universo ficcional, proliferam robôs e inúmeros engenhos tecnomecânicos e protagonistas que cada vez mais derivam e povoam ambientes digitais. Tais manifestações do imaginário, notadamente, provocam reflexões sobre a realidade vivida. Neste sentido, é sob a perspectiva da semiótica peirceana, que perscruta semioses como dinâmica viva de processos criativos e intelectivos, que nos propomos a examinar algumas figurações desse universo do pós-humano, notadamente, em duas produções culturais endereçadas ao público juvenil.

Palavras-Chave: humano; cyberpunk; cibercultura; crossover; Peirce

It is a fact that the technological revolution of recent times has potentially provoked unprecedented mutations in the most diverse domains of human life. The operated transformations have a profound effect on social, cultural and anthropological conditions; new subjectivities are generated and intelligence technologies become increasingly able to shelter them, in the context of adaptive communities. These challenges motivate the search for ways to understand the complexities that this new context evokes. In a close dialogue with this reality, representations are projected, especially in the arts. Cultural productions aimed at youth reception are shown as privileged territory for manifestations of an imaginary that allies with

\footnotetext{
* Professora Doutora da Universidade de São Paulo, Programa de Estudos Comparados de Literaturas de Língua Portuguesa /FFLCH/USP, São Paulo, Brasil. ORCID: 0000-0003-0102-4445.

** Professora Doutora do programa de Mestrado Interdisciplinar em Ciências Humanas da Universidade de Santo Amaro - São Paulo, Brasil.ORCID: 0000-0003-3474-9434.
} 
representations of a stage which is being called posthuman. In narratives that harbors this fictional universe, robots, countless techno-mechanical devices and protagonists who increasingly derive and populate digital environments proliferate. Such manifestations of the imaginary, notably, provoke reflections on the lived reality. In this sense, it is from the perspective of Peircean semiotics, which peers semioses as a living dynamic of creative and intellectual processes, that we propose to examine some figurations of this posthuman universe, notably, in two cultural productions addressed to the youth audience.

Keywords: human; cyberpunk; cyberculture; crossover; Peirce.

Data de receção: 2020-04-16

Data de aceitação: 2020-09-01

DOI: $\underline{10.21814 / 2 i .2617}$ 


\section{Tecnologia e pós-humano}

Pode tornar-se instrutivo lembrar que os desafios e ideias aqui expostos não se constituem novidade, uma vez que somos partícipes das inauditas experiências que agenciam a nossa vida contemporânea. É fato que ainda nos causam algum espanto os processos devastadores, entre povos e culturas, que promovem violências identitárias, atos potencialmente desestabilizadores do que entendemos por convivência humana. Mal compreendemos as novas subjetividades sendo geradas em contínua mutação diante das tecnologias da inteligência que se tornam cada vez mais maleáveis em um contexto de comunidades adaptativas (Santaella, 2010), em face das revoluções tecnológicas e paradigmáticas, que vimos emergir. Nossa inserção na cibercultura é um aspecto incontornável. Se a Revolução Industrial provocou inovações, a Revolução Digital vem propiciando transformações, antes inimagináveis, aos processos de informação e comunicação, e está potencialmente mudando todas as esferas da sociedade no que diz respeito à vida humana, tanto em âmbito psíquico, quanto social e antropológico, desafiando-nos à compreensão das complexidades que esse novo contexto nos encerra.

São bem-vindas as reflexões de Giorgio Agamben (2009), para quem é verdadeiramente contemporâneo aquele que não coincide perfeitamente com este tempo, nem está adequado às suas pretensões e é, portanto, nesse sentido, inatual; mas, exatamente por isso, exatamente em razão deste deslocamento e desse anacronismo, ele é capaz, mais que os outros, de perceber e apreender o seu tempo. Diante do quadro de incerteza que se nos afigura, são várias as hipóteses explicativas a ancorar as discussões acerca das mutações dos últimos séculos. Para Bruce Mazlish (citado em Warrick, 1977), estamos na iminência de descartar a quarta descontinuidade que sustentava nossa imagem como seres eleitos. É considerável a síntese proposta pelo antropólogo americano: Copérnico nos desloca do centro do universo; depois, Darwin nos devolve à condição animal; em seguida, Freud nos desilude da racionalidade e, por último, desfaz-se a oposição com a máquina. A descoberta do DNA - veículo informacional - traz a ressemantização do termo "vida" ao romper com o dualismo máquina e humano informação é um denominador comum e os transcende.

No seio das reconstituições da vida cultural e social, há questões que vêm ocupando a mente de teóricos e também a imaginação de artistas. Entre elas podem ser apontadas algumas como: há uma tentativa de superar o humano? O homem está condenado à obsolescência? Do que se constitui a identidade humana em um contexto de programação em alta tecnologia? $\mathrm{O}$ que é a realidade em meio às recorrentes possibilidades de simulação? Como se redefine o humano? A pauta das discussões, desse modo, passa a compreender inferências concernentes à expressiva crise do humanismo moderno, à fragmentação do homem, as redefinições das fronteiras do humano em função de uma ressemantização do mundo a cargo da tecnologia, à eminência de uma nova antropomorfia. Este último questionamento incide sobre quem é esse humano do século XXI e aponta para o fato de o corpo humano ter-se tornado problemático e alvo de inquietações.

São indagações a suscitar reflexões acerca do imaginário do pós-humano e as interações, interdependências e hibridizações entre homens e máquinas (ciborguização, biônica, robótica), incluindo aspectos relativos à redefinição do humano, por meio da manipulação genética ou da digitalização das redes neuronais, tendo como propostas questões prementes acerca das representações do humano na contemporaneidade.

Se entre os desafios do humano está o de refletir sobre sua condição no contexto de sua época, surgem conjecturas e hipóteses que se alinham para procurar entender, nesta contemporaneidade, as transformações que ele está sofrendo e potencialmente sofrerá. 
Nesse sentido, as problemáticas não só colocam sob foco as descobertas das ciências, as invenções tecnológicas, mas, por extensão, colocam o corpo humano sob interrogação. Máquina e organismo, antes domínios apartados, parecem aproximar-se, pondo em questionamento a vida ou sua permanência, em face da inexorabilidade da morte. Nesse sentido, o imaginário cumpre seu desígnio na organização de uma lógica de sentimentos, de pensamentos e de motivações para ações capazes de reconfigurar o humano. As artes em geral e a literatura de ficção científica em específico constituem terrenos férteis para a expressão desse imaginário.

Na esteira de Santaella (2003), ao se eliminar a materialidade da equação homem animal, o corpo é questionado como mera carne. Parece, segundo a autora, haver índices de uma consciência que foi surgindo gradativamente do estatuto do corpo humano "como fruto de sua crescente ramificação em variados sistemas de extensões tecnológicas até o limiar das perturbadoras previsões de sua simulação na vida artificial e de sua replicação resultante da decifração do genoma." (Santaella, 2003, p. 182) A esse corpo sob interrogação a semioticista denomina corpo biocibernético. É no âmbito dessas indagações que as interfaces do corpo-mente com suas virtualizações vão mobilizar a convergência de noções e o uso genérico da expressão "pós-humano".

O fato é que o modelo cibernético do organismo humano e de sua identidade tornouse muito potente, vindo a influenciar noções de corpo que lhes foram subsequentes, notadamente as que aparecem nas intermitentes imagens do cyborg. Este aparecia como entidade reversível, pois os dispositivos criados poderiam ser incorporados nas cadeias de feedback regulatório do corpo humano. O termo Cyborg foi cunhado em 1960 por Manfred E. Clynes e Nathan S. Kline, para designar os sistemas homem-máquina autoregulativos como solução para as alterações das funções corporais ao se acomodarem a ambientes diversos, a exemplo, o controle de problemas que as viagens espaciais podiam impingir sobre a neurofisiologia do corpo humano.

$\mathrm{Na}$ base do imaginário do corpo, sob o efeito de suas interfaces com a tecnologia, abrem-se novas fronteiras para mirar o ser humano imerso em uma era pós-biológica, pós-humana. A ligação entre externo e interno torna-se inevitável e propõe a combinação mente e matéria, homem e máquina. Ao transgredir as fronteiras que separavam o natural do artificial, o orgânico do inorgânico, o Cyborg, por sua própria natureza, "questiona os dualismos, evidenciando que não há mais nem natureza nem corpo, pelo menos no sentido que o iluminismo lhes deu. " (Santaella, 2003, p. 187)

Dada a abertura polissêmica que disso ressoa, há um translado da noção para discussões sobre a política do corpo. Neste sentido, cumpre lembrar o impacto causado, em 1985, pelo texto polêmico de Donna J. Haraway - que propõe uma reflexão sobre a influência da ciência e da tecnologia do final do século XX sobre as relações sociais. Em O Manifesto cyborg, a bióloga aponta para a encarnação de um futuro aberto às ambiguidades e às diferenças, criticando dualismos.

O cyborg - criatura formada por fusões entre máquina e organismo, mistura de realidade social e ficção e não constituindo corpo sólido com componentes definidos seria uma metáfora dessa nova política em um mundo marcado de forma crescente pelo binômio ciência e tecnologia, no qual as fronteiras entre humano e animal, organismo e máquina, físico e não-físico mostram-se fluidas. Para a autora, borrar essas fronteiras seria um modo de repensar dominações hierárquicas.

As dicotomias mente/corpo, natureza/cultura, macho/fêmea e organismo/máquina, além de emoção/razão, matéria/espírito, natural/artificial, anteriormente tão rígidas, vão sendo então destecidas, dando espaço a conceitos maleáveis e passíveis de reconstruções. O processo de remodelamento de corpos e de relações mostra como os corpos são construídos e podem ser desmontados, colocando à prova sua suposta naturalidade e 
revelando suas possibilidades políticas. Nesses termos, se a figura do cyborg move contestações apoiadas na resistência aos dualismos, viria contribuir para a construção de um mundo a favor das diversidades.

Com a elucidação das complexas conexões entre cibernética e corpos e por meio da visibilidade conferida a inúmeros arranjos possíveis de subjetividade e de organismos, Haraway procura ampliar o conceito de biopolítica de Foucault. A interface entre Ciência e Tecnologia rompe dualismos que estruturavam o eu ocidental e a estabilidade do poder patriarcal, territórios antes invioláveis. Isto se alinha ao pensamento acadêmico, quando, sob o descontrutivismo proposto por Jacques Derrida, viriam a ser criticados os sistemas simbólicos do ocidente fundados em oposições binárias, desmascarando hierarquias filosóficas reforçadoras de critérios de verdade pré-estabelecidos.

O fato é que, com a dissolução de categorias analíticas, chaves de nosso entendimento, do qual derivava a divisão entre biológico e tecnológico, natural e artificial, entre outras, a identidade do corpo humano tornou-se controversa. As misturas e as muitas possibilidades de descorporificação, recorporificação, expansões não-carnais da mente abrem um campo volátil em constante devir em razão dos avanços das tecnologias e de suas consequências para a realidade do corpo humano. As novas configurações surgem, ampliam-se, nem sempre nos causam espanto, tampouco reflexões sobre a ocorrência desses processos, é o caso da telepresença em que se torna possível ver com os olhos de uma máquina e manipular o mundo físico (robôs); o caso do desenvolvimento de partes artificiais do corpo, a configuração protética, o uso de membros mecânicos controláveis por impulsos nervosos; a nanotecnologia, que implica a criação de máquinas a partir de moléculas para operar no corpo humano; das redes neurais que engendram sistemas computacionais com habilidade para aprender com a experiência, baseadas no funcionamento do cérebro; além da manipulação genética.

Enquanto as investigações das ciências e da tecnologia somam-se nesse campo voltado para a crescente ramificação de extensões tecnológicas e a inserção do corpo nessa era que se denomina pós-humana, o imaginário evidencia-se como rede simbólica indissociável de sua concretização material, engendrando realidade e ficção também no universo das Artes.

A sétima arte constituiu terreno fértil para a recepção do cyborg, que já inspirava o imaginário literário. The Six Million Dollar Man, Neuromancer e The Matrix são exemplos emblemáticos que explicitam a passagem do cyborg híbrido (orgânico e maquínico) para o cyborg como simulação digital (fluxos informativos e avatares). Esse limiar mais recente do cyborg "tem apontado para a direção de formas de existência póscorporais e vem recebendo a denominação de Pós-Humano" (Santaella, 2003, p.191). O desdém em relação ao físico e a fascinação por formas em que a carne se mostra irrelevante, se comparada à memória, são condições dessa dissolução de fronteiras e do desafio eletrônico para a definição do sujeito.

Nosso cotidiano é permeado de fenômenos advindos das revoluções. Gerimos informação e mobilidade de ordem planetária, temos acesso exponencial a essa rede sem fios e somos dotados de capacidade cognitiva para explorá-la; interagimos com objetos que se conectam de forma autônoma, a própria internet é um híbrido de humanos e não humanos. Somos, em grande parte de nosso dia, guiados por cidades inteligentes, uma vez que a tecnologia nos fornece informação para que possamos agir com mais precisão durante o percurso. Não é por acaso que o próprio corpo humano se tornou problemático e se anuncia uma nova antropoformia. Mas é na ficção científica e em outros gêneros e subgêneros ficcionais, que as variantes imagináveis entre o humano e a máquina e suas consequências são colocadas sob o ponto de vista da perplexidade e no âmbito da provocação do sensível e da intelecção. As artes, seguramente, constituem formas de 
expressão que trataram das angústias dos homens, a literatura, a pintura, a fotografia, o teatro, o cinema, a hipermídia, são manifestações potentes do imaginário de sua época.

Constituindo-se como um tipo de literatura de ficção científica, o cyberpunk faz figurar o corpo carnal em constructos informáticos. A influência desse gênero literário no cinema foi fundamental para a disseminação do que hoje se compreende por "cibernético". Considerado como uma visão de futuro, o cyberpunk comporta uma ambiguidade - por vezes nostálgico, romântico e anti-tecnológico e por vezes deslumbrado com objetos proporcionados pela tecnologia per se. Engloba literatura, música, cinema, teorias, a cultura jovem e a cultura da MTV e a cultura do PC/Macintosh e vincula-se a nomes como Mary Shelley, Philip K. Dick e J.G. Ballard, Gibson e outros escritores, McLuhan, Wiener, Walter Benjamin e Baudrillard como teóricos e a música de Patti Smith, Lou Reed, Ramones, Sex Pistols (a geração punk) como fontes de sua influência. Ao aglutinar a perspectiva distópica do movimento punk com o imaginário futurista, o cyberpunk ganha forma e força visionária.

Essas criações ficcionais denotam resistência em dois âmbitos: no social, provocando reflexões acerca das mudanças advindas pela alta tecnologia, e no individual, tecendo críticas às mutações do corpo e das subjetividades.

Lemos (2002) afirma que a contracultura e a sociedade de massa contribuíram para o aparecimento dos cyberpunks como precursores da cibercultura, por meio de uma atitude contestadora, com a proposta de descentralização da ciência e da tecnologia.

McCarron (1995) acredita ser irônico o fato de que o capitalismo seja o responsável pela literatura de fantasia moderna, mas que, ao mesmo tempo, ele seja agredido por ela. Em geral, as narrativas cyberpunks ocorrem em um futuro relativamente próximo, em um espaço social caótico de megalópoles, em que grandes corporações portadoras de alta tecnologia coexistem com gangues de rua. Nessas histórias, a tecnologia não é privilégio das classes dominantes, mas, pirateada, confere poder e possibilidade de subversão do sistema. A associação da ficção científica com outros estilos e figuras do movimento punk converge para propostas de descentramento das conhecidas estruturas de poder.

De fato, é na vertente do pós-humanismo crítico que essas complexas discussões tomam forma, tangenciando problemáticas que engendram a natureza da realidade e das identidades.

Segundo Adriana Amaral (2004), o cyberpunk comporta múltiplas características, muitas delas herdadas do romantismo gótico. O sublime tecnológico e o neogrotesco, o cyborg e a cidade são os três elementos centrais que caracterizam essa estética.

Com base no conceito de sublime formulado por Burke como "[...] aquilo que desafia a compreensão racional invocando uma mistura de prazer e terror no espectador" (Burke citado em Dery, 1999, p. 160), Joseph Tabbi (1995), ao verificar que tal efeito estético persiste na época contemporânea como figura de poder emotivo, mas mediado agora pela ciência e pela tecnologia, como um prazer complexo derivado da dor da insuficiência representacional, produziu um dos modos de escrita moderna na América - um sublime tecnológico - , que pode estar situado, conceitual e temporalmente, entre a Educação, de Henry Adams, e o Manifesto Cyborg, de Donna Haraway (Tabbi, 1995, p.1).

Em vez de sublime tecnológico, Dery (1999) define a estética da cibercultura como Neo Grotesca. Este implica o corpo, carne, o sangue, a matéria humana como tônicas que nos convocam a confrontar com o fato inelutável de nossa mortalidade. A presença de seres híbridos, humanos e máquinas, em um cenário caótico, de identidade sombria, um lugar poluído e desorganizado é a forma como a cidade converte-se distopicamente em metáfora para o ciberespaço em várias produções culturais. $\mathrm{O}$ grande útero metropolitano encontra-se infectado pela tecnologia, necrosado e em vias de ser abandonado, tentando converter-se em dados, bytes, em informação pura a fim de transcender sua existência 
física em direção à alucinação consensual (Gibson, 1984) chamada ciberespaço. Essa cidade obscura, de atmosfera sombria e perigosa, faz reverberar o imaginário decadentista na literatura, nos filmes, nos videoclipes, nos games.

As histórias dos homens talvez não sejam mais que um incessante corpo-a-corpo com os dipositivos que eles próprios produzem - e, antes de qualquer outro, a linguagem. $\mathrm{O}$ ser vivo, ao encontrar a linguagem e pondo-se nela sem reservas, exibe o seu gesto irredutível a ela, aposta no jogo lúdico com simulacros. No caso dos exemplos a que vimos nos referindo, no âmbito das produções ficcionais, é notável como a convergência de linguagens, a configuração do espaço caótico na narrativa, os seres híbridos que encarnam personagens, a vampirização sígnica, que transforma corpos em silhuetas multiformes, estetizam o choque e levam à reflexão.

Reconhecidamente, a literatura, o cinema, bem como outras formas da produção cultural de recepção juvenil constituem-se como vasto território inclinado para essas manifestações ficcionais do pós-humano e de seus avatares. Nesse universo imaginário, proliferam robôs e todo o tipo de engenhos tecno-mecânicos cada vez mais digitais. Não raro, as fronteiras do humano (à escala do jovem, como é evidente) e do pós-humano se esbatem a favor de criaturas fantasiosas, como é muito típico dos imaginários densos.

\section{Figuras do pós-humano na produção de recepção juvenil}

Ao abordar produções culturais contemporâneas voltadas a jovens, inevitavelmente nos deparamos não só com obras que apontam para momentos de transição e rupturas, mas também com aquelas que abordam questões identitárias e acenam para a possibilidade de identidades híbridas. São narrativas que, notadamente, agradam tanto o público jovem, como estabelecem um profícuo diálogo com o universo do adulto. Seguramente, porque trazem, em seu bojo, aspectos relacionados a problemáticas existenciais e sociais humanas desafiadoras e exibem reflexos desses seres que somos - em constante processo de formação e transformação - o que não escapa nem aos menos avisados. Além disso, é instrutivo assinalar que o número de leitores adultos de obras juvenis tem se tornado muito expressivo, sabe-se que em razão de procedimentos estéticos de que lançam mão seus criadores e dos recursos híbridos e complexos próprios das linguagens e dos suportes que as engendram.

Esse é o território do fenômeno denominado crossover fiction, entendido como conjunto de textos que, pela potencialidade de serem acessados, apreciados e interpretados por crianças, jovens e adultos, atravessam fronteiras estabelecidas, conforme aponta Sandra Beckett (2009).

É comum denominar-se crossover produções ambientadas nas diversas mídias e plataformas, ocorrendo, nestes casos, um cruzamento no interior da narrativa com a configuração de um espaço propício em que mundos ficcionais distintos interagem na nova obra; com limites da fronteira temporal rompidos pela ocorrência de eventos simultâneos, pela reversibilidade que se torna possível; pelo conjunto de personagens que migram de universos pré-existentes ou vêm protagonizar ações em ambientes híbridos e absolutamente desconhecidos, criando narrativas enviezadas e universos expandidos.

Se, como diz Falconer (2010), crossover resulta do desenvolvimento e transformação da sociedade atual, em que a diluição de fronteiras entre grupos etários, o rápido desenvolvimento tecnológico e científico e a globalização provocariam uma expressiva mudança na compreensão da identidade humana, cumpre lembrar que, embora o termo seja empregado recentemente, o fenômeno a que se refere pode ser observado em produções de outras épocas, constatação, notadamente, feita pelos estudos da área de 
literatura infantil e juvenil. Processos análogos encontramos em obras como As mil e uma noites, Robinson Crusoé, de Defoe, Alice's adventures underground e as demais Alices de Lewis Carroll, Viagens de Gulliver, de Jonathan Swift, entre outras, como é o caso dos contos de fadas e ou maravilhosos que compõem um cânone expressivo da Literatura para crianças e jovens. Estes, derivados de narrativas primordiais e anônimas advindas, em grande parte, das manifestações orais, não foram endereçados a crianças ou jovens, mas circulavam entre o conjunto de ouvintes (adultos e crianças) durante noites de inverno em torno de fogueiras ou em cabanas de camponeses. Época em que não era necessário um código secreto para falar sobre tabus, sendo confiada à narrativa uma naturalidade na abordagem de elementos voltados ao amor, ao sexo, à morte, aos problemas sociais. Em suma, eram narrativas que dispunham "o manto diáfano da fantasia" sobre a nudez da realidade, alimentavam o mistério que a arte de narrar e fabular gesta para tecer e retecer a vida humana.

A título de reflexão e apreciação crítica, selecionamos duas produções culturais contemporâneas que ultrapassam o endereçamento a um determinado público, abrindo-se a experiências plurais de leitura: WALL-E e L3.0

$W A L L-E$, película americana lançada em 2008, ganhou Oscar de melhor filme de animação em 2009. Dirigida por Andrew Stanton e Alan Barillro, conta a história de um pequeno robô, o último deixado na Terra - uma vez que toda a população fora enviada a outro planeta -, que tinha como tarefa limpar a sujeira produzida pelos humanos.

Com uma estrutura narrativa linear, as personagens inserem-se em um cenário arruinado - um planeta abandonado e sujo pelo lixo, projetando sinais de um imaginário apocalíptico. A personagem principal - WALL-E (Waste Allocation Load Lifter Earthclass) - Levantador de Carga da Alocação de Resíduos Classe-Terra - é um pequeno robô, de "olhos grandes" e "estatura" reduzida - similar a de uma criança -, de tronco na forma de pacote de lixo, o que traduz sua missão na Terra: limpar o planeta coletando o lixo deixado pelo excesso de consumo motivado por uma megacorporação, a empresa Buy-n-Large (BnL), a qual desiste de cuidar do ecossistema, preferindo transferir a população, por cinco anos, para Axiom, uma nave estelar.

A história se passa em 2105, entretanto, em 2110, ninguém pôde retornar, pois o ar da Terra mostrou-se tóxico, impossibilitando a vida. Desse modo, toda a humanidade permaneceu indefinidamente no espaço.

WALL-E faz amizade com uma barata - inseto ancestral e noturno, que sobrevive e se adapta facilmente em ambientes de sujidade e de catástrofes naturais. A personageminseto, afetivamente construída, aproximando-se do espectador sempre em movimento de zoom, auxilia o protagonista em sua tarefa diária. Certo dia, encontram uma planta crescendo no lixo e a levam para casa - denotando a possibilidade de revigoração da vida naquele ambiente inóspito.

A iluminação amarelada predominante na película, que projeta uma atmosfera de solidão e morte, contrapõe-se diametralmente com a tonalidade viva e revigorante da planta, provocando um estranhamento, que leva o espectador, a partir do contraponto, a repensar a trajetória do humano na Terra e seu nefasto domínio sobre a natureza.

A paixão de WALL-E por EVA (Extraterrestrial Vegetaton Evaluator), uma robô tecnologicamente mais avançada aponta para a necessidade de criar laços. O nome EVA remete ao imaginário bíblico com o qual se movimenta a intenção de se dar um par ao protagonista para que possa construir, a partir do trabalho e em harmonia, uma nova humanidade - ideia reforçada pelas imagens da Arca da Aliança. O propósito da meninasonda-robô é encontrar sinais de vegetação na Terra. Agora, o movimento é inverso, pois o humano já habitou o planeta e necessita reinaugurá-lo. 
O tempo de espera até que a nave venha buscar EVA é o suficiente para eles se conhecerem e criarem laços, fazendo com que o protagonista se agarre externamente à nave para acompanhá-la a Axiom. Ali, o conforto excessivo propiciado pelo mundo robótico subtrai a vontade dos humanos, tornando-os obesos mórbidos e inaptos para o mundo do trabalho e, por consequência, para a transformação do estado de coisas que demanda intervenção. O comandante da nave entrega tudo ao controle de Auto, o piloto automático - séria crítica ao estilo artificial de vida daqueles habitantes escravizados à tecnologia, apartados da natureza, alienados daquilo que os faz humanos. Se mãos e braços se tornam inúteis, inaptos para trabalhar para o mundo e para o outro, de fato, $o$ homem perde sua liberdade para atuar.

A trilha sonora mostra-se criativamente singular, com efeitos extraídos de situações inusitadas, como o ruído do abrir e fechar de algemas, para sinalizar a fala da barata, motores de carro, ruídos de inicialização de computador, movimento de carrinhos de supermercado, tudo isso associado a sons orquestrais, sustentando a preocupação com um tom emotivo a engendrar a magia da narrativa, que segue uma espécie de jornada de novas aprendizagens.

Com personagens sem fala, em estreito diálogo com o cinema mudo de Chaplin, o motivo da viagem e da jornada do herói se sustenta na aventura de transformar o destino do homem na Terra.

A canção Put On Your Sunday Clothes, do musical Hello, Dolly!, que trata de dois jovens que buscam o amor, também faz reverberar, em intertexto sonoro e imagético (porque WALL-E encontra um vídeo do filme), a relação dos dois robôs. Assim também ocorre com a música La vie en Rose. Uma cena, em especial, destaca-se pela magia, beleza visual e pela sensação afetiva que evoca, a do balé de WALL-E e EVA, no espaço, próximo à nave.

$\mathrm{Na}$ animação, que hibridiza a magia dos contos de fadas com cenários ciberpunk, o imaginário projeta uma lógica de sentidos e sensibilidades questionadores das identidades dos humanos e de seus fazeres e afazeres na vida terrena.

Stanton, com sua formação cultural cristã, constrói a narrativa com elementos simbólicos presentes em seu imaginário individual e é com ele que também desperta coletivamente uma recepção mais ampla, capaz de ultrapassar fronteiras de idade, tempo e lugar. Busca o vigor de fontes míticas, que, de alguma maneira, fazem reverberar o humano em nós, ao privilegiar imagens da criação - poiésis - como forma de construção ficcional, salvaguardando a razão em sua expressão sensível.

No bojo do mito, circundam imagens da corporeidade, simbolizações que estabelecem vínculos com o mundo e com o outro - valores para os quais o filme acena.

A identidade heroica de WALL-E, ao lado de sua companheira EVA, atesta uma forma de combate à angústia da finitude e da morte para a qual todos os humanos se curvam. É no âmbito dessa dimensão simbólica, que sustenta a lógica desse imaginário ficcional atravessado por motivos míticos, que um novo movimento de hominização é passível de ocorrer.

Sem minimizar a prontidão crítica necessária neste momento da evolução da espécie humana, quando o cerne da vida pode ser manipulado, quando o design da encarnação dessa vida está em jogo nas mãos do humanos e suas ambições, uma produção como WALL-E coloca a questão do vivo como um problema candente e de forma deveras interessante. O protagonista é um boneco com versão de monitoramento dos movimentos, domínio do espaço, com reações a estímulos sensoriais capazes de coletar e classificar objetos - uma máquina com gestos apropriados para manipular o mundo físico. Se, como robô, foi construído para que operadores o monitorassem, e que sua conexão com o humano se processasse por via informacional - ideia de presença remota - que liga a 
inteligência humana a robôs menos inteligentes e responsivos, capazes de realizar ações no mundo, o que se verifica na constituição desse personagem é a consecução de uma engenharia robótica que produziu uma máquina a atingir autotomia (knowbots/ mobots) e que demonstra capacidade de desenvolver aprendizagem, experiência tão essencial aos seres inteligentes.

Verifica-se, pelas ações protagonizadas por WALL-E, uma propensão para tornar-se um ser social, capaz de fazer escolhas e tomar decisões. Além da demonstração de afeto e desejo de sobrevivência. Ora, tais consequências poderiam advir de possíveis combinações entre a vida artificial, robótica, redes neuronais, manipulação genética em que a distinção da vida natural e artificial perderia sua balize, indicando que muitas funções vitais poderiam ser replicáveis maquinicamente, ou de outra forma, que máquinas poderiam adquirir funções vitais. $O$ fato é que o efeito do conjunto desses desenvolvimentos tem recebido o nome de pós-humanismo - denominação que vem destecendo as distinções entre o artificial e o natural, o real e o simulado, o orgânico e o mecânico.

Nesta linha de raciocínio, WALL-E, um produto do imaginário ficcional, encarna o desejo do pós-humano e, ultrapassando os horizontes da carne, capacita-se no vórtice das mutações para uma militância pelo admirável perfume da vida.

A narrativa ambientada em dois espaços - o terrestre e o ambiente espacial - invoca a presença de contradições a que os humanos se submetem, em inventivo jogo especular e dialético: o robô é movimento de busca da organização e da vida, seu ser é o tempo da narrativa que se tece com esse movimentar-se, enquanto os humanos, instalados em uma nave, são formas estáticas, monopolizadas e repetitivas, tal espectro da morte. Esses deslocam-se pela nave que os transporta do sistema que destruíram. Por outro lado, como assinatura, deixam algo que foram capazes de criar: uma criatura que puxará o fio da narrativa da vida.

De fato, entretece-se, nessa animação, um conjunto de questões candentes que se ligam a: tempo, narrativa, amor, morte. Questões postas pela história de uma máquina. Questões apresentadas em uma película bastante atual. Cenário em que reverberam fios de outras histórias. Tem-se: a coragem, o enfrentamento, a qualidade adaptativa de Robinson Crusoé (este e sua amizade por sexta-feira, WAAL-E com a companhia do inseto que o segue); as sátiras inscritas nas viagens de Gulliver, que viabilizam perspectivas diversas de pensar um mesmo fato; as estranhas aventuras de Alice por insólitos diálogos, estranhos personagens, espaços fantásticos geridos por uma espantosa lógica; o engenhoso jogo de luz e sombra de Eros e Psiquê - nas instâncias amorosas que velam o mistério de nossa busca na completude do ser. Além desses índices, há outros movimentos intertextuais com a história do cinema.

Ademais, a animação coloca sob mira aspectos relacionados a interpretações acerca da criação do mundo - as duas hipóteses se tecem na configuração ficcional da narrativa - a perspectiva evolucionista e a perspectiva criacionista. Pela primeira, o homem seria o ancestral da máquina; pela segunda, sua existência estaria proposta no Gênesis, de uma maneira ressignificada por EVA.

Nesse sentido, podemos evidenciar uma densa conjunção de imaginários na composição desse filme: o científico, com a presença das máquinas e da tecnologia; o mítico, portador da linguagem e da vida; o fabular, engendrando uma linguagem capaz de figurar reflexão e exemplaridade; o do conto, com uma narrativa que tece as demandas da existência e os encantos da fantasia; o cinematográfico, com temas, intertextos e recursos de imagem em movimento. Em suma: a animação desvenda-se como um "quasedocumento folclórico, ora uma quase-crônica da vida urbana, ora o quase-drama do cotidiano burguês, ora o quase-poema do imaginário às soltas, ora, grafia brilhante e 
preciosa voltada às festas da linguagem" (Bosi, 1994, p.7). De certa forma, cumpriria o destino da ficção contemporânea.

Em estreito diálogo com $W A L L-E$ e com o tema do robô solitário no mundo pósapocalíptico, entretanto com uma composição ainda mais densa e de gradiente de maior vigor estético se apresenta a animação francesa produzida e dirigida por Alexis Decelle, Cyril Declercq, Vincent Defour e Pierre Jury, em 2014, intitulada L3.0. O curta narra a história de um robozinho em uma cidade, Paris, aparentemente abandonada, cuja busca é o lúdico. Diferentemente da animação de Wall-E, neste texto cinematográfico, tempo, morte e vida são questões colocadas de forma poética, ambígua, mas profundamente angustiante.

Somos introduzidos a um cenário urbano por meio de um jogo de múltiplos enquadramentos (da cidade, da casa, da janela, da sala), o ponto de vista da câmara envolve e leva o espectador do mundo exterior (da paisagem da cidade adormecida) até o interior de uma casa (de ambiente aconchegante), onde o robô e um urso de pelúcia assistem à TV.

Em seguida, o brinquedo e o robô diante de um jogo de tabuleiro compõem uma cena que provoca sentimento intenso de solidão. É época de Natal - festa de nascimento. Uma celebração cultuada há muito pela civilização ocidental. Entretanto não há mais humanos para a comemoração em família. O silêncio do jogo e do ambiente repleto de brinquedos é eloquente em face da ausência de crianças. É o robô quem simula a presença da infância, com estatura reduzida e cabeça grande, acompanhado pelo urso de pelúcia, com o qual ele busca interagir.

Segue-se a cena em que o robozinho escreve em folhas brancas, "Hello, my name is Leo; Please come play with me ", dobra o papel, faz várias dobraduras em forma de aviões. Um close em um carrinho de madeira puxado por alguém motiva a inferência de um movimento para a área externa. O robô, em um lugar privilegiado, oferece-nos uma visão aérea da cidade. Lança seus aviõezinhos ao horizonte da paisagem. Um movimento se faz no sentido contrário. Aproxima-se dele uma borboleta, pousa em seu "dedinho". De volta ao ambiente interno, esse ser alado, dono do movimento, mas também representante de metamorfoses, passa, depois de colocado em uma redoma de vidro, a ser um modelo vivo para a confecção da dobradura, possivelmente entretenimento predileto do robô, atividade que requer precisão, coordenação e exatidão para repetir formas.

A borboleta é uma imagem central na narrativa, uma vez que é o único ser vivo que entra em cena. Símbolo de liberdade e transformação, acena para a qualidade de sentimento despertada pela arte - diálogo que se apresenta, com muita densidade, nas cenas finais, em que as dobraduras em diversas formas levam a um quarto onde se veem corpos sem vida, em uma composição que lembra Guernica, de Picasso. Apresentada várias vezes em zoom e sutilmente em forma de sombra movimentando-se nas cenas iniciais, o animal condensa um princípio articulador e ponto de virada do roteiro.

No episódio em que o robô faz a dobradura à semelhança da borboleta, há uma proposição deveras ambígua, que evoca sensações acerca de uma relação possível: ser a dobradura à semelhança da borboleta - seu modelo; ser a dobradura o modelo para o devir da borboleta. Em suma, pode isto se reduzir à relação fundamental: vida / morte. A vida é representada pelo movimento e pela liberdade, a morte acontece paulatinamente à medida que estes vão se esvaindo; de qualquer forma, nasce dessa descontinuidade, dessa ruptura, a percepção da diferença - modo pelo qual emerge um conteúdo fundamental com a negação da vida. Nesta sequência da narrativa, a transformação de um estado a outro produz um diálogo com a Estética, de alguma forma, tem-se cumprida a noção de que a Arte se constrói com a morte do referente. 
Um fadeout corrompe a cena, o espectador vai ser conduzido ao descartar do corpo do inseto; na sequência, metonimicamente, acompanha-se a mãozinha do robô colocando a dobradura recém produzida junto a muitas outras. Um traveling nos conduz a outro cômodo da casa. Nessa passagem, há um espelho, neste, antes da passagem do robozinho, nota-se o reflexo de um ser humano - uma silhueta branca com as duas mãos na cabeça - denotando desespero; vê-se, depois, o reflexo da imagem do robô, atravessa-se um portal, acessa-se outro espaço, no qual estão dispostos muito espectros (corpos, entre os quais vários humanos), algo similar aos realizados pela técnica ou arte da dobradura.

A cena, à semelhança de um retrato monocromático, com ausência de cor, como um quadro tecido de retalhos ou fragmentos, ou como se uma "collage" de papéis compusesse a obra. Cumpre-se a intertextualidade com Guernica, de Picasso, com um efeito análogo: de forte agonia, sensação de devastação e desumanidade.

O curta parece endereçado a um público infantil e juvenil, no entanto impacta o universo adulto. Evoca uma participação sensível e intelectiva de seu interlocutor. Propõe, seguramente, reflexões bastante potentes sobre a nossa época.

Engenho e arte se entramam na realização narrativa. Arte, técnica e virtualidade arquitetam, com engenhosidade, uma narrativa, em que o tempo também protagoniza eventos e aparece em cena: pela trilha sonora e pela marcação das horas naquilo que o encarna em nossa civilização - o relógio. Máquina que compartilha como o robô o espaço e o tempo, as imagens e o ritmo: "Este é um tempo de silêncio. Tocam-te apenas." reverbera o poema de Hilda Hilst (Abreu, 2007, p. 21).

A linearidade da narrativa é rompida pela concorrência de pistas intertextuais, pelo tecido das várias linguagens e pela confluência de traços advindos de universos múltiplos, conjunto de elementos que, pelo processo de montagem conceitual, evoca grande reflexão. De fato, a produção traz uma via provocativa: a de se pensar em um "limite, entre uma fase e outra" - desafio enfrentado talvez pelo robô protagonista e, mais severamente, pelos humanos.

Essa configuração da produção artístico-cultural contemporânea, que, ao fim e ao cabo, projeta uma rede de forças dinâmicas, realidades virtuais, rastros digitais, isolamento social, compõe a lógica do pós-humano e vem agenciando a produção de recepção juvenil. O fato é que essa multiplicidade indiscernível provoca também inquietações e mobiliza hipóteses. Nossa era comporta uma condição das artes em que não há mídias privilegiadas para as expressões artísticas, o que aponta para a ampliação do espectro das artes e para a disseminação de estilos, formas e práticas que geriram, nessa imensa variedade, um tanto de riqueza e hibridismo, consubstanciando trocas entre imagens novas e ancestrais que passam a engendrar nossa memória.

\section{Considerações finais}

Se o assunto que nos ocupou neste artigo, como de início colocamos, não traz novidades, posto reforçar indagações e desafios que nos ocupam em face de nossa contemporaneidade, cabe registrar que as discussões empreendidas revelam forte preocupação com o tratamento conceitual e analítico das encruzilhadas que vimos experimentando nesse contexto dinamizado pela emergência de novas tecnologias, pela dinâmica da globalização e pelo desencadeamento de novas subjetividades que colocam sob interrogação o status do ser humano. Com o olhar para os jovens e para a produções culturais a que acessam, vimos, sem minimizar as especificidades das artes e das comunicações, perscrutar algumas vias interatuantes, que as levam a habitar territórios comuns. Nesse sentido, entendemos haver uma convergência entre comunicações e artes 
que nos parece convocar para um campo de atividade crítica que se volte para a nova estética que está a surgir.

Com essa perspectiva, nossas pesquisas fundamentam-se em teorias que permitem enlaçar fronteiras do conhecimento. Entre essas, a teoria peirceana, que agencia uma forma singular de perscrutar semioses, essa dinâmica viva, evolutiva e multiplicadora que engendra processos criativos e intelectivos, abrindo perspectivas teóricas de acesso ao imaginário e às artes contemporâneas - arcabouço teórico que nos motiva a valorar positivamente a multiplicidade e a diversidade crescentes, bem como a apostar na possibilidade de uma disposição para o poder sensório, perturbador e cognitivamente transformador da arte.

Importa reforçar como o fenômeno crossover tem agenciado formas de recepção fronteiriças desses produtos culturais contemporâneos, uma produção híbrida, análoga à configuração de nossa época, em que distopia e utopia se friccionam e onde a alternância entre o maravilhoso e a face dark do ciberpunk se faz de modo, notadamente, harmônico.

Através dos séculos, entre outras formas de conhecer, a Arte vem testemunhando experiências vitais dos seres humanos. Como modo de expressão, de conhecimento, de crítica, de resistência, de denúncia e iluminação, do grotesco ao sublime, ela condensa imaginários carregados de representações culturais, cuja síntese articula visões do universo particular direcionadas para a possibilidade de apreensão do ser humano em âmbito universal.

A produção artística contemporânea desenha-se por uma lógica de imaginários tecida por uma rede de linguagens e camadas densas de sentidos organizadas pelo princípio da complexidade. A arte consubstancia um fazer não mais reconhecível apenas em formas que gozem de privilégios. Não é mais à pintura a óleo, ao mármore, à pedra, ao metal, à palavra que se reservam as forças do material para receber a expressão criadora. Agregam-se à pintura, a fotografia, o holograma, o vídeo, entre outros fazeres artísticos, que, em jogo de linguagens, acenam para uma nova compreensão do humano.

Não é por acaso que os artistas exploram tais searas, sem minimizar o assombro, e, nesse momento evolutivo da espécie, investem no desenvolvimento de uma percepção singular, capaz de proporcionar uma prontidão crítica em favor do desvio de rotas, aguçando sensibilidades para o papel vital que a arte tem a desempenhar no jogo da vida - em especial, quando o design desta vida, posto na mão dos humanos, está em jogo.

\section{REFERÊNCIAS}

Abreu, C. F. (2007). Limite branco. Rio de Janeiro: Agir.

Agamben, G. (2009). O que é o contemporâneo? e outros ensaios. São Paulo: Argos; Santa Catarina: Chapecó.

Amaral, A. (2004). Espectros da ficção científica. A herança sobrenatural do gótico no cyberpunk. Revista Verso e Reverso, $38 . \quad$ Consultado em http://www.versoereverso.unisinos.br/index.php? $=2 \& \mathrm{~s}=9 \& \mathrm{a}=15$.

Bosi, A. (1994). O conto brasileiro contemporâneo. São Paulo: Ed. Cultrix.

Beckett, S. (2009). Crossover fiction: Global and historical perspectives. New York/London: Routledge. 
Dery, M. (1999). The Pyrotechnic insanitarium: American culture on the brink. NY: Grove Press.

Falconer, R. (2010). Young adult fiction and the crossover phenomenon. In David Rudd (ed.). The Routledge Companion to Children's Literature. New York: Routledge.

Gibson, W. (1984). Neuromancer. New York: Ace Books.

Lemos, A. (2002). Cibercultura: Tecnologia e vida social na cultura contemporânea. Porto Alegre: Sulina.

Mccarron, K. (1995). Corpses, animals, machines and mannequins: The body and cyberpunk. In Mike Featherstone \& R.Burrows (eds.). Cyberspace Cyberbodies Cyberpunk. London: Sage.

Martins, M. L.,Miranda, J.B, Oliveira, M. \& Godinho, J. (2011). Imagem e Pensamento. Coimbra: Grácio Editor.

Santaella, L. (2003). Culturas e artes do pós-humano, da cultura das mídias à cibercultura. São Paulo: Paulus.

Santaella, L. (2007). Linguagens líquidas na era da mobilidade. São Paulo: Paulus.

Santaella, L. (2010).A Ecologia Pluralista da Comunicação. Conectividade, mobilidade, ubiquidade. São Paulo: Paulus.

Tabbi, J. (1995). Postmodern sublime. Technology and american writing from Mailer to cyberpunk. London: Cornell University Press.

Warrick, P. (1977). Images of the man-machine inteligence relationnship in science fiction. In T. D. Clareson, (org). Many futures, many worlds: Theme and form in science fiction. Kent $(\mathrm{OH})$ : The Kent State University Press.

\section{Referências audiovisuais}

Decelle, A., Declercq, C., Defour, V. \& Jury, P. (2014). L3.0. França: Isart digital.

Morris, J. \& Stanton, A. (2008). WALL-E. Emeryville, CA: Pixar Animation Studios. 